\title{
Experimento sociolinguístico sobre percepções do soar gay
}

\author{
Antonio ACKEL $\bullet$ \\ Universidade de São Paulo (USP)
}

\section{RESUMO}

Esta resenha apresenta o experimento que Ronald Beline Mendes, professor e pesquisador da Universidade de São Paulo e bolsista produtividade do CNPq, tem desenvolvido com foco na noção de percepção sociolinguística do soar gay. Sua apresentação dividiu-se em três partes: a primeira descreve os pressupostos teóricos adotados sobre a relação indicial entre elementos linguísticos e significados sociais; na segunda parte, são reportados os resultados de uma enquete de opiniões, desenvolvida em São Paulo, sobre o que significa "soar gay"; e, por último, são apresentados os resultados de sua pesquisa de percepção em que associações entre forma linguística e significados sociais são feitas implicitamente.

OPEN ACCESS

EDITADO POR

Raquel Freitag

REVISADO POR Dany Thomaz Gonçalves

DATAS

Recebido: 28/06/2020

Aceito: $29 / 06 / 2020$

Publicado: 06/07/2020

COMO CITAR

Ackel, A. (2020).

Experimento sociolinguístico sobre percepções do soar gay. Revista da Abralin, v. 19, n. 02, p. $1-6,2020$.

\section{ABSTRACT}

This review presents the experiment that Ronald Beline Mendes, professor and researcher at the University of São Paulo and CNPq productivity fellow, has developed with a focus on the notion of sociolinguistic perception of sounding gay. His presentation was divided into three parts: the first describes the theoretical assumptions adopted about the indexical relationship between linguistic elements and social meanings; in the second part, results of an opinion survey carried out in São Paulo of opinions about what it means to "sound gay" are reported; in the third part, Mendes presents the results of his perception research in which associations between linguistic form and social meanings are made implicitly. 


\section{REVISTA DA ABRALIN}

\section{PALAVRAS-CHAVE}

Sociolinguística. Percepção de fala. Soar gay.

\section{KEYWORDS}

Sociolinguistics. Speech perception. Sound gay.

A conferência A percepção sociolinguística do soar gay, proferida por Ronald Beline Mendes, inserese na terceira onda da sociolinguística. O exemplo mais citado desse tipo de abordagem é a pesquisa de William Labov, na década de 1960, sobre falantes de Martha's Vineyard. Nela, está a ideia de que membros de comunidades ou grupos empregam formas da língua relacionadas a intenções de natureza social. Há, entre elementos linguísticos e significados de natureza social, relação que confere especificidades a performances sociolinguísticas.

Um dos significados sociais explorados na terceira onda relaciona-se à relação entre uso da linguagem e gênero/sexo dos falantes. Nessa linha é que Mendes (USP/CNPq) trabalha pelo menos desde a primeira década do ano 2000. É exemplar de sua produção a tese de livre docência Percepção e performance de masculinidades: Efeitos da concordância nominal de número e da pronúncia de /e/ nasal (2018). Sua conferência foi mais uma instigante reflexão sobre a percepção social que os falantes têm em relação ao "soar gay".

Mendes iniciou sua apresentação lançando luz à discussão sobre o significado social das formas linguísticas. Entre diálogos de falantes e ouvintes, destacou que percepções acerca do modo de falar do outro são compartilhadas por associações entre formas linguísticas e significados sociais. Variantes linguísticas, de forma geral, funcionam como índices de significados sociais, e a relação indicial de formas linguísticas não é nem necessária, nem essencial. O modo de falar pode estimular percepções em ouvintes, como educado, feio, inadequado, gay etc. Um elemento linguístico tem, portanto, diversos significados sociais, que podem mudar de acordo com práticas de uma comunidade específica de falantes.

Como exemplo, pode-se associar a ditongação de [o] em [oi] e a palatalização de [s] em [S] na palavra [goiftı] à fala carioca. No entanto, a sequência [oif] não é exclusivamente carioca. Foi registrada como "fala carioca" por sua coocorrência, ou seja, com o passar do tempo, fixou-se como uma das marcas do que hoje se reconhece como tal.

Retomando o objetivo da apresentação, Mendes observou que não se deve pensar sobre formas linguísticas características dos gays. Uma particular forma linguística não é tão somente gay. Ser gay e soar gay são circunstâncias diferentes, assim, considera-se a possibilidade de ser gay e não soar como tal.

Com relação aos estudos de gênero (OCHS, 1993), Mendes adverte para que não se estabeleça relação elementar entre formas linguísticas e identidades sociais, porém, ao lado de pesquisadores 


\section{REVISTA DA ABRALIN}

de diferentes áreas (GAUDIO, 1994; SMYTH; ROGERS, 2001; SMYTH et al., 2003), questiona "quais elementos linguísticos levam um ouvinte a achar que um certo falante soa gay?"

Mendes desenvolveu uma pesquisa que consistia no preenchimento de formulário, a partir da audição de leituras de texto. Cinco homens tiveram suas vozes gravadas em áudio, lendo texto redigido pelo próprio pesquisador. A gravação foi ouvida por 106 pessoas que atribuíram notas de 1 a 5 (1, menos gay; 5, mais gay) para cada leitura. Mendes (2007) notou certa homogeneidade, apesar da esperada variação nas notas. Seu objetivo, no entanto, foi saber dos ouvintes a razão da atribuição de suas notas, especialmente das mais altas. As repostas, em geral, foram: i. porque os homens pareciam ser mais "efeminados"; ii. porque a entoação deles subia e descia muito rápido durante a leitura - fenômeno linguístico conhecido como dinamismo de pitch; iii. porque alongavam as vogais.

Curiosamente, alguns ouvintes responderam que os homens pareciam gays por usarem diminutivos, no entanto, o texto não trazia tais ocorrências. Comentários como "gay fala certinho", "não comete erros" chamaram atenção, já que se pode dizer que tal característica não seja exclusivamente gay. Estimulados por leituras de texto que não continha erros, ouvintes consideraram falantes como parte de um conjunto de estereótipos. Por meio de observações de que gay fala certo ou não comete erros, verificou-se que os exemplos que ouvintes utilizaram para explicar, em sua maioria, foram os de concordância nominal $(\mathrm{CN})$.

Em estudos sobre esse assunto, Mendes destacou os de Scherre $(1978 ; 1988)$ sobre a correlação entre escolaridade e classe social: quanto mais a alta a classe social, menor tendência de utilizar a concordância não padrão (CNø); de Brandão e Vieira (2012) sobre a correlação sexo/gênero: homens tendem a usar mais a forma não padrão do que mulheres; de Oushiro (2015) sobre correlações entre escolaridade e sexo/gênero na fala paulistana, em que se observa que pessoas com maior grau de escolaridade tendem a empregar menos a CNø e que homens tendem a usar mais essa concordância.

No projeto SP2010, orientado por Mendes, foram observados resultados das 60 entrevistas sobre formas da CN e sua atribuição ao modo de falar paulistano. Mendes notou que em nenhum desses estudos houve associação a sexo/gênero quando os informantes foram questionados sobre o que achavam da expressão "um chopes e dois pastel". Fato que difere de seu primeiro estudo, descrito no início dessa resenha, em que, a partir de leituras e das razões das notas atribuídas, algumas respostas foram sobre $\mathrm{CN}$ e a associação de erros: quanto mais erros o falante cometia em seu discurso, mais ele soava masculino e, de outro modo, quanto menos erros, mais feminino soava.

Labov (2006[1966]), em pesquisa sobre a fala de Nova Iorque, verificou respostas mal articuladas por parte de ouvintes sobre suas percepções acerca de um certo jeito de falar, pois os informantes, por não possuírem vocabulário técnico, não conseguiam avaliar precisamente a fala. Influenciado pelos comentários labovianos, Mendes apresentou seu experimento de percepção, pelo qual tem verificado associações que pessoas fazem implicitamente entre forma linguística e significado social. A partir do estudo que revelou a percepção de ouvintes de que gay fala "corretamente" e do fato de que os exemplos foram de $\mathrm{CN}$, perguntas que definiram o experimento de percepção com foco na CN foram "Seria um homem percebido como alguém que soa menos masculino diante da concordância nominal padrão (CNp)?", "Seria um homem que soa efeminado percebido como alguém que 


\section{REVISTA DA ABRALIN}

soa menos efeminado diante de CNø?", "Seria um homem que soa masculino percebido como alguém que soa menos masculino diante da CNp?"

Na busca por respostas, Mendes extraiu trechos das falas de quatro paulistanos gravados pelo projeto SP2010. Todos enunciaram todos os sintagmas nominais na sua versão padrão, por exemplo, "meus amigos, alguns poucos, das mães etc." Por meio do programa computacional de análise e síntese de fala Praat, de Paul Boersma e David Weenik, Mendes excluiu o /s/ do elemento à direta, criando uma versão não padrão dos trechos enunciados: "alguns evento, dos pai, os condômino etc." Essa técnica, conhecida como matched-guise (LAMBERT et al., 1960; CAMPBELL-KIBLER, 2006) permite criar estímulos nas leituras, quais sejam, CNp e CNø.

O experimento teve continuidade com o preenchimento de formulário sobre como soaram, para 100 ouvintes, aqueles trechos específicos. Nele, constavam seis escalas de diferenciais semânticos de "nada até muito" e incluía noções de escolarização, amigabilidade, efeminidade, formalidade, inteligência e classe (alta ou baixa). Além disso, o ouvinte deveria marcar no formulário quais características poderiam ser aplicadas ao informante e, dentre elas, destacou-se especialmente a característica ser gay.

Na distribuição das respostas do componente "efeminidade", quando estimuladas por sintagmas nominais, na CNø, as respostas tenderam a aumentar. Isso significa que o conjunto de quatro falantes soou mais efeminado quando ouvidos no estímulo padrão. Mendes ainda procurou identificar correlação entre respostas com variável linguística envolvida, a CNp. A partir de um gráfico sobre distribuição empírica de dados para os quatro falantes, respostas tenderam a aumentar, quando estimulados com CNp. De outro modo, diante da CNø, os homens foram percebidos como menos efeminados.

O estudo mostrou que além de funcionar como índice de baixa escolaridade e classe socioeconômica, CNø também indicia masculinidade, ou seja, CNp aponta para percepção de efeminidade na fala masculina. No entanto, ainda que CNø tenha se apresentado como estereótipo de baixa escolaridade/classe, não é possível afirmar que seja estereótipo de masculinidade, pois, como afirmou Mendes, "paulistanos não desenvolvem comentários metalinguísticos sobre gêneros quando lhes fazemos perguntas diretas sobre concordância nominal". Por outro lado, há relação entre CNø e baixa escolaridade/classe e, talvez, essa característica aponte para expressão de masculinidade. Enquanto no caso da CNp, obtiveram-se significados sociais de "esmero" e "cuidado", interpretados pelas avaliações das leituras descritas no início da apresentação.

A conferência, ao destacar o significado social de uso da língua em relação ao "soar gay", um dos assuntos do livro de Mendes e Levon, publicado pela Oxford University Press, Language, Sexuality and Power, não deixa de abrir espaço para a discussão existente entre os sociolinguistas sobre terceira onda. Há perspectivas críticas elaboradas principalmente por sociolinguistas que se preocupam com busca de padrões gerais de variação. De qualquer modo, a observação da construção e recepção de identidades linguísticas tem sido um dos hotpoints da pesquisa sociolinguística. Não à toa, Eckert (2012) aponta ser a terceira onda um desvio de rota na área. Caberá ao futuro dizer se essa vertente de estudos chegará à conciliação com outro caminho clássico da sociolinguística: a relação variação e mudança. 


\section{REVISTA DA ABRALIN}

\section{REFERÊNCIAS}

A percepção sociolinguística do soar gay. Conferência apresentada por Ronald Beline Mendes [s.l., s.n], 2020.1 vídeo (2h 04min 0s). Publicado pelo canal da Associação Brasileira de Linguística. Disponível em https://www.youtube.com/watch?v=WIX811OY5Z8\&t=4026s. Acesso em: 20 jun 2020.

BRANDÃO, S.; VIEIRA, S. Concordância nominal e verbal: contribuições para o debate sobre o estatuto da variação em três variedades urbanas do português. Alfa, Revista Linguística, São José Rio Preto, vol. 56, n.3, p.1035-1064, https://dx.doi.org/10.1590/S198157942012000300013. Acesso em: 20 jun 2020.

CAMPBELL-KIBLER, K. The nature of sociolinguistic perception. Language Variation and Change, Cambridge, vol. 21, n. 1, p. 135-156, mar. 2009. https://doi.org/10.1017/S0954394509000052. Acesso em: 20 jun 2020.

ECKERT, P. Three waves of variation study: The emergence of Meaning in the Study of Variation. Annual Review of Anthropology, Stanford, vol. 41, p. 87-100, 2012. https://doi.org/10.1146/annurev-anthro-092611-145828. Acesso em: 20 jun 2020.

GAUDIO, R. P. Sounding gay: Pitch properties in the speech of gay and straight men. American Speech, vol. 69, p. 303-318, 1994

LABOV, W. Padrões sociolinguísticos. São Paulo: Editora Parábola, 2008 [1972].

LABOV, W. The Social Stratification of English in New York City. Cambridge: Cambridge University Press, 2009 [1966]. https://doi.org/10.1017/CBO9780511618208

LAMBERT, W. E., HODSON, R. C., GARDNER, R. C. \& FILLENBAUM, S. 'Evaluational reactions to spoken languages'. Journal of Abnormal and Social Psychology, vol. 60 (1), p. 44-51, 1960.

MENDES, R. B. What is 'gay speech' in São Paulo, Brazil. In: SANTAEMILIA, J.; BOU, P.; MARUENDA, S.; ZARAGOZA, G. (Orgs.) International Perspectives on Gender and Language. València: Universitat de València 2007.

MENDES, R. B.; Levon, E. Language, Sexuality and Power. Studies in Intersectional Sociolinguistics. New York: Oxford University Press, 2016.

MENDES, R. B. Diminutivos como marcadores de sexo/genero. Revista Linguística. v8, n. 1, junho de 2012, p. 113124 .

MENDES, R. B. Percepção e performance de masculinidades: Efeitos da concordância nominal de número e da pronúncia de /e/ nasal. Tese (Livre-docência em Sociolinguística) - Faculdade de Filosofia, Letras e Ciências Humanas, Universidade de São Paulo, São Paulo, 2018.

OCHS, E. Constructing Social Identity. Research on Language and Social Interactions. n. 26, vol. 3, p. 287-306 1993.

OUSHIRO, L. Identidade na pluralidade: avaliação, produção e percepção linguística na cidade de São Paulo. 2015. Tese (Doutorado em Semiótica e Linguística Geral) - Faculdade de Filosofia, Letras e Ciências Humanas, Universidade de São Paulo, São Paulo, 2015. https://doi:10.11606/T.8.2015.tde-15062015-104952. Acesso em: 20 jun 2020.

SAUSSURE, F. Curso de Linguística Geral. São Paulo: Cultrix, 1969[1916]. 


\section{REVISTA DA ABRALIN}

SCHERRE, M. M. P. Reanálise da concordancia nominal em portugueŝ. 555f. Tese (Doutorado em Linguística) Universidade Federaldo Rio de Janeiro, Rio de Janeiro, 1988.

SMYTH, R. \& ROGERS, H. Searching for phonetic correlates of gay- and straigh-sounding voices". Toronto Working Papers in Linguistics, v. 8, p.44-64, 2001.

SMYTH, R.; JACOBS, G. \& ROGERS, H. (2003). Male voices and Perceived Sexual Orientation: An experimental and theoretical approach. Language in Society, v. 32, n. 3, p. 98-127, 2003. 